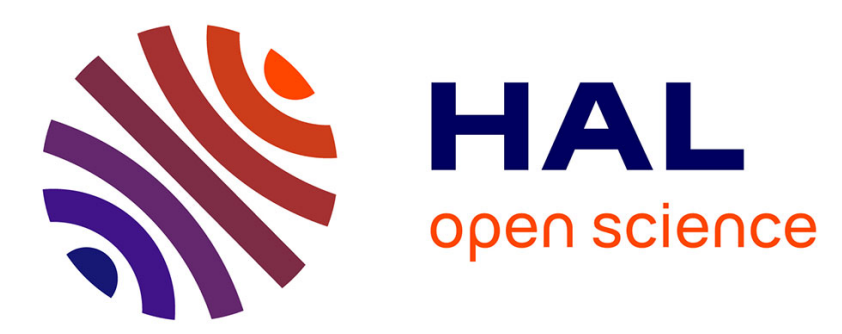

\title{
Pulsed corona plasma source characterization for film deposition on the inner surface of tubes
}

Ramasamy Pothiraja, Nikita Bibinov, Peter Awakowicz

\section{To cite this version:}

Ramasamy Pothiraja, Nikita Bibinov, Peter Awakowicz. Pulsed corona plasma source characterization for film deposition on the inner surface of tubes. Journal of Physics D: Applied Physics, 2010, 43 (49), pp.495201. 10.1088/0022-3727/43/49/495201 . hal-00576622

\section{HAL Id: hal-00576622 \\ https://hal.science/hal-00576622}

Submitted on 15 Mar 2011

HAL is a multi-disciplinary open access archive for the deposit and dissemination of scientific research documents, whether they are published or not. The documents may come from teaching and research institutions in France or abroad, or from public or private research centers.
L'archive ouverte pluridisciplinaire HAL, est destinée au dépôt et à la diffusion de documents scientifiques de niveau recherche, publiés ou non, émanant des établissements d'enseignement et de recherche français ou étrangers, des laboratoires publics ou privés. 


\title{
Pulsed corona plasma source characterization for film deposition on inner surface of tubes
}

\author{
Ramasamy Pothiraja, Nikita Bibinov and Peter Awakowicz \\ Institute for Electrical Engineering and Plasma Technology, Ruhr-Universität Bochum, \\ 44801 Bochum, Germany \\ E-mail: ramasamy.pothiraja@rub.de, nikita.bibinov@ rub.de and awakowicz@aept.rub.de
}

\begin{abstract}
A microplasma jet has been constructed for chemical vapor deposition on inner surface of narrow long tubes and is tested on a quartz tube with the inner diameter of $6 \mathrm{~mm}$ and the outer diameter of $8 \mathrm{~mm}$. A long plasma filament $(>100 \mathrm{~mm})$ is generated inside the tube in argon with methane admixture. Depending on the quantity of admixture in argon, the negative as well as the positive corona discharges are ignited. Both modes of plasma are characterized using optical emission spectroscopy. For this purpose, nitrogen is admixed with argon and its emission is used for the determination of gas temperature, electron velocity distribution function, and electron density at various places along the axis of the tube. The formation of active species, like $\mathrm{C}, \mathrm{C}_{2}, \mathrm{CH}$, etc. during the dissociation of methane, is observed through their characteristic emission. The rate of methane dissociation is determined at various places along the axis of the tube during both modes of discharge. Since the chemical kinetics of film growth process is different, different kinds of films are obtained during different modes of discharge.
\end{abstract}

\section{Introduction}

Coating thin films on inner surface of tubes improves their functionality in many ways without changing the bulk properties. It yields commercial tubes with value-added properties such as biocompatibility, hydrophilicity and corrosion or permeation resistance as in the following cases, 1. Depositing the fluorinated carbon on PVC tubes enhances the biocompatibility for the blood circulating tubes [1,2], 2 . Silica coating on PTFE tube increases the wettability of the tube about 3 times [3], 3. Carbon or titanium nitride film as protective coating on inner surface of a metallic tube improves its lifetime [4-6], 4. Deposition of silica on inner surface of PET tubes or bottles reduces the permeation of gases [7,8], 5. Titania coating on inner surface of glass tube improves its surface properties to be suitable for microfluidic devices $[9,10], 6$. Coating of nickel/alumina film on inner surface of silica tube and plasma treatment of resultant film increases the catalytic activity of this film for carbon nanofiber synthesis [11]. Thin film deposition on inner surfaces of tubes is one of the challenging processes in modern plasma technology. Several research groups have reported a systematic development of this process and coated various films like $\mathrm{SiO}_{2}$ and $\mathrm{TiO}_{2}$ on inner surface of various metal, quartz, PET and PTFE tubes [1-13]. Mostly microwave or RF driven ICP, CCP and jet based microplasma or magnetron plasma sources were used for their studies. Generally, in several plasma coating methods, precursors are decomposed in the confined electrode region where the plasma is active, the chemically active species are transported inside the tube to be coated and film coating is carried out by gas flow. In this case, because of polymerization during the transport process, as the distance is increased from the plasma generation point, size of the chemically active species (constituent of polymer film) usually gets increased. Because of this reason, size of depositing chemically active species is different at different places along the axis of the tube. This phenomenon could reduce film uniformity along the axis of the tube. 
Our strategy for film coating on inner surface of the tubes is to construct a microplasma jet, in a way that it should produce a long filament of plasma in a gas containing a precursor as an admixture. This long filament has to be generated inside the tube to be coated, so that the precursor will be dissociated to produce active species for polymerization at close vicinity of the inner surface of the tube. In this case, the filament of plasma, which is thinner than the diameter of the tube to be coated, is active for long distance in the region of film coating. All the precursors do not get decomposed at one place. Instead, they get decomposed everywhere along the axis of the tube within close vicinity of the inner surface of the tube. This may reduce the differences in the size of depositing chemically active species at different places along the axis of the tube and possibly lead to uniform film deposition.

In this regard, the microplasma jet has been constructed and the long filament of plasma ( $>100 \mathrm{~mm})$ is generated inside the tube in the presence of a precursor. Since plasma characterization is the primary step in optimizing PECVD process for a coating of any kind of film, the plasma generated in our microplasma jet is characterized including a measurement of the electron density $\left(\mathrm{n}_{\mathrm{e}}\right)$, the electron velocity distribution function (EVDF) and the rate of electron impact dissociation of precursor at different places along the axis of the tube (filament axis) as these have strong influence on the film properties. In this paper, we report the following, 1. the configuration of our microplasma jet, 2. generation of the positive as well as the negative pulsed corona discharges by varying the quantity of the precursor in the plasmaforming gas [14], 3. characterization of these modes of plasma using optical emission spectroscopy (OES), numerical simulations, microphotography and voltage-current measurements, 4 . determination of quantity of the precursor dissociated during these different modes of plasma at various places along the axis of the tube, 5. determination of various active species produced for the polymerization and 6. preliminary characterization of the film deposited on the inner surface of the tube.

\section{Experimental setup and simulations}

\subsection{Experimental setup}

Our microplasma jet consists of a tungsten inner electrode with a diameter of $1.6 \mathrm{~mm}$. One end of this electrode is sharpened (spike) to a cone angle of $30^{\circ}$, while the other end of the electrode is connected to a high voltage generator (Redline Technologies G2000). The output voltage and the pulse frequency of this generator can be controlled and varied from $0-20 \mathrm{kV}$ and from $4-500 \mathrm{kHz}$, respectively. Each high voltage pulse exhibits a sequential profile with damped oscillations. A tube made of quartz with the inner diameter of $6 \mathrm{~mm}$, is used in order to test the feasibility of film deposition and to characterize the plasma ignited in this setup. This tube is placed around the tungsten electrode (figure 1). A copper tube is used as a grounded electrode. It is placed around the quartz tube and is axially separated from the inner electrode. The distance between the inner tungsten and the outer copper grounded electrodes can be varied along the axis of the quartz tube. For all the experiments reported in this article, the grounded electrode is fixed at 43 $\mathrm{mm}$ from the spike of the tungsten electrode. A void is present in the grounded electrode, through which information of the filament generated inside the quartz tube is obtained. Since collisional cross section of methane is known, its dissociation rate constant can be determined from the EVDF. With this, not only quantity of methane dissociation determination, but also polymer chain growth as well as film deposition can be simulated. Hence, methane is used as the precursor and it is passed along with argon. For a diagnostic purpose, nitrogen admixture is also passed along with argon and methane mixture. Relatively and absolutely calibrated echelle spectrometer (ESA 3000) is used to obtain the emission spectra [15]. The 
solid angle of the optical fiber used in echelle spectrometer amounts to $0.012 \mathrm{sr}$. Spectral resolution of the echelle spectrometer amounts to $\Delta \lambda=0.015 \mathrm{~nm}$ at $\lambda=200 \mathrm{~nm}$ and $\Delta \lambda=0.060 \mathrm{~nm}$ at $\lambda=800 \mathrm{~nm}$. The groove density of echelle grating, $\mathrm{g}=75$ grooves per $\mathrm{mm}$. Echelle spectrometer is working in 100 spectral orders of grating (from 30th up to 130th). A Pearson current monitor (model, 6585; output, $1 \mathrm{~V}=1 \mathrm{~A}$ ) is used for plasma current measurement, which is mounted around a cable connecting the generator and the tungsten electrode. The output of the current monitor is connected to an oscilloscope (LeCroy 9450). The actual voltage applied for plasma generation is measured by connecting the output of the generator to the oscilloscope through a voltage divider with the dividing factor of 2000 . The pulse frequency is fixed as 22 $\mathrm{kHz}$ for all the experiments. For the plasma volume determination, a high speed sensitive CCD camera (PCO sensicam qe) is used. The spatial resolution of CCD camera amounts to $100 \mu \mathrm{m}$. A FTIR spectrometer (BRUKER VECTOR 33) with the resolution of $0.3-1 \mathrm{~cm}^{-1}$ is used to characterize the film deposited on the inner surface of the tube. Background measurement in atmospheric air is carried out in the transmittance mode along with uncoated quartz tube in a specially made tube (sample) holder. FTIR measurement of film coated tube in the transmittance mode is carried out after background measurement. Background corrected spectrum of film coated tube is considered as a spectrum of coated film. [16,17]. There is a reproducibility problem in the region below $2000 \mathrm{~cm}^{-1}$, due to the strong absorption of quartz tube. Hence only the region above $2000 \mathrm{~cm}^{-1}$ is considered for our analysis.

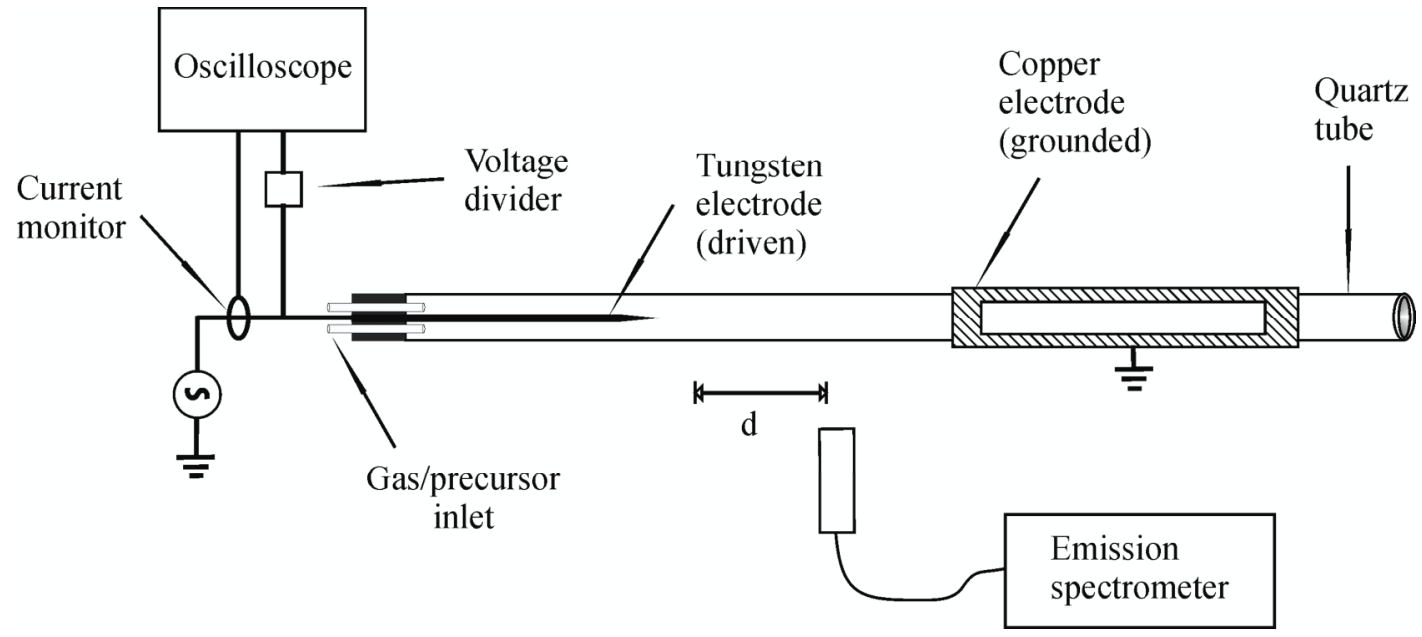

Figure 1. Schematic view of the experimental setup.

\subsection{Determination of gas temperature}

Gas temperature in active plasma volume is one of the important parameters, because of its influence on gas density in plasma and on the rate constants of chemical reactions. The rotational temperature of diatomic molecules is considered as the gas temperature, since the rotational and the translational degrees of freedom have equal temperatures because of very fast rotational relaxation at atmospheric pressure. For the determination of gas temperature, the rotational intensity distribution in the emission of neutral nitrogen molecule $\mathrm{N}_{2}\left(\mathrm{C}^{3} \Pi_{\mathrm{u}}, v^{\prime}=0 \rightarrow \mathrm{B}^{3} \Pi_{\mathrm{g}}, v^{\prime \prime}=0\right.$ ) (abbreviated as $\mathrm{N}_{2}(C-B, 0-0)$ ) is used. The emission spectrum is measured perpendicular to the axis of the filament, as shown in figure 1. Since the spectral resolution of our echelle spectrometer is not high enough to determine the intensities of the separate rotational lines in the emission spectrum of neutral nitrogen molecules, the rotational temperature is determined by a fitting procedure. For this purpose, we calculate the intensity distribution in the emission 
of $\mathrm{N}_{2}(C-B, 0-0)(\lambda=337.1 \mathrm{~nm})$ for different values of rotational temperature using the program code developed for this purpose [18]. By comparing the measured emission spectra with the calculated spectra for various rotational temperatures, we determine the actual rotational temperature of nitrogen molecule with an inaccuracy of $\pm 30 \mathrm{~K}$.

When high concentration of the precursor is used, there is an overlap in the emission of $\mathrm{N}_{2}(C-B, 0-0)$ with the emission of $\mathrm{NH}$ radical at some places along the axis of the tube (filament). Hence, in this case, the rotational intensity distribution in the emission of $\mathrm{CN}$ radical, $\mathrm{CN}\left(\mathrm{B}^{2} \Sigma^{+}, v^{\prime}=0 \rightarrow \mathrm{X}^{2} \Sigma^{+}, v^{\prime \prime}=0\right)(\mathrm{CN}(B-$ $\mathrm{X}, 0-0)$ ) is used for the determination of gas temperature. In this case also, the rotational temperature is determined by the fitting procedure. In this regard, we simulate the intensity distribution in the emission of $\mathrm{CN}(B-\mathrm{X}, 0-0)(\lambda=388.3 \mathrm{~nm})$ for different values of rotational temperature using the program LIFBASE [19]. The rotational temperature of $\mathrm{CN}$ radical is determined with an inaccuracy of $\pm 30 \mathrm{~K}$.
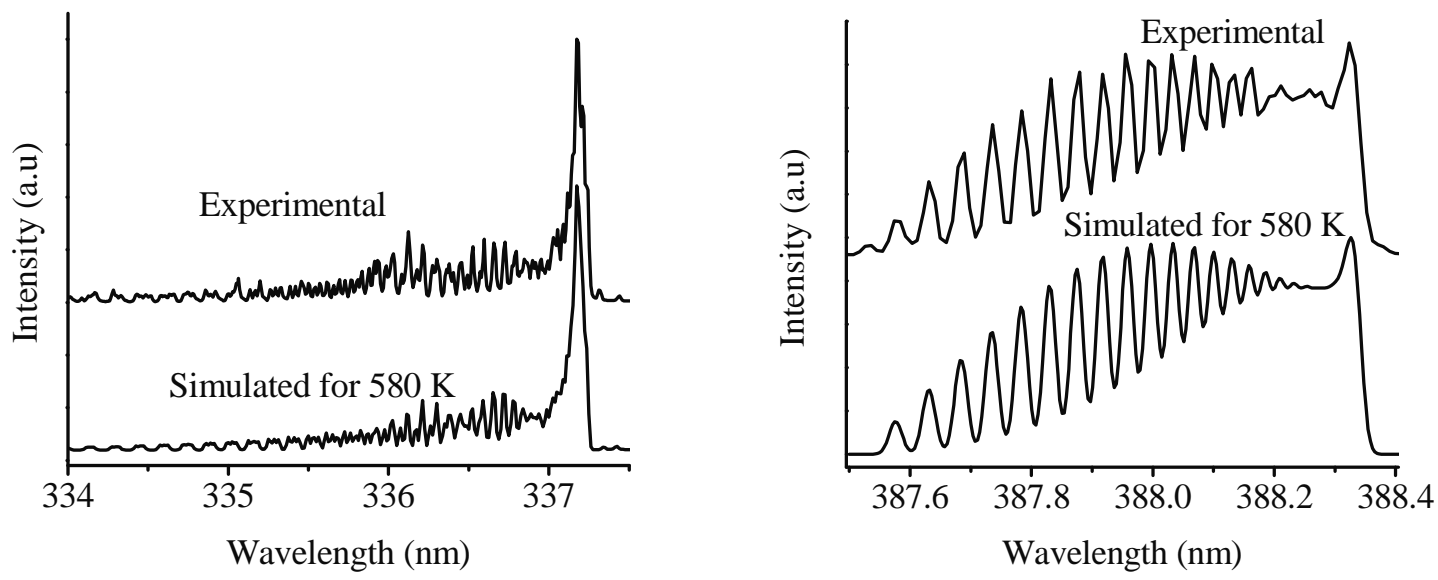

Figure 2. Comparison of gas temperature determined by using the emission of $\mathrm{N}_{2}(C-B, 0-0)$ (left) and the emission of $\mathrm{CN}(B-\mathrm{X}, 0-0)$ (right) from the same emission spectrum measured during the positive corona discharge (Ar, 99.74\%; $\mathrm{N}_{2}, 0.14 \% ; \mathrm{CH}_{4}, 0.12 \%$; total gas flow rate, $2170 \mathrm{sccm}$ ) at $102 \mathrm{~mm}$ away from the spike of the tungsten electrode. For ease of comparison, base lines of experimental spectra are shifted above the simulated spectra.

Under our experimental condition, molecular emissions $\mathrm{N}_{2}(\mathrm{C}-\mathrm{B})$ and $\mathrm{CN}(\mathrm{B}-\mathrm{X})$ are excited by electron impact as well as by collisions with argon metastable atoms. The molecular momentum of diatomic molecules changes slightly by electron impact excitation. The contribution of argon metastables on the absolute intensity as well as on the rotational distribution of the emission $\mathrm{N}_{2}(\mathrm{C}-\mathrm{B})$ is calculated. It shows that excitation due to argon metastable has a strong contribution on the absolute intensity of nitrogen emission. In this case, the rotational distributions in the excited states $\mathrm{N}_{2}(\mathrm{C})$ and $\mathrm{CN}(\mathrm{B})$ can be very different from rotational distributions at gas temperature. It can be approximately described by equilibrium distribution with temperature of about 2000K [20,21]. Rotational distribution in measured emission spectrum is formed by initially excited distribution and competition of spontaneous emission, rotational relaxation and quenching process by collisions with surrounding argon atoms. To study the influence of this factor on the reliability of measured gas temperature, we simulate the emission spectrum of $\mathrm{N}_{2}(\mathrm{C}-\mathrm{B})$ for our experimental conditions with assumption that all "second positive system" in nitrogen emission spectrum is excited by collisions with argon metastables. To simulate the rotational relaxation, we use the rate constants determined in theoretical and experimental studies of rotational relaxation of nitrogen molecules in ground state by collisions with surrounding argon atoms [22]. The measured rotational distribution in $\mathrm{N}_{2}(\mathrm{C})$ excited during collisions with argon metastables [20], and rate constant for 
quenching of $\mathrm{N}_{2}(\mathrm{C}-\mathrm{B})$ emission in argon [23] are used for this simulation. After simulation of $\mathrm{N}_{2}(\mathrm{C}-\mathrm{B})$ emission spectrum, we determine the rotational temperature using Boltzmann plot and estimate the deviation of determined value from the gas temperature assumed for our simulation. For our experimental conditions, this difference amounts to about $1 \%$ (e.g. $6 \mathrm{~K}$ at gas temperature of $600 \mathrm{~K}$ ), which is much lower than the inaccuracy of $\pm 30 \mathrm{~K}$ of our fitting procedure.

The $\mathrm{CN}$ molecules are produced in $\mathrm{Ar} / \mathrm{CH}_{4} / \mathrm{N}_{2}$ mixture through a multi-step reaction. The exact mechanism of formation and the rotational distribution of $\mathrm{CN}(\mathrm{B})$ state is not known in the literature. Therefore the rotational relaxation could not be simulated. However, because of the equal rotational temperatures of emission of $\mathrm{N}_{2}(\mathrm{C}-\mathrm{B})$ and $\mathrm{CN}(\mathrm{B}-\mathrm{X})$ measured using the same emission spectrum (see figure 2) and very fast relaxation of $\mathrm{CN}(\mathrm{B})$ in argon observed at low pressure conditions [24], we assume that $\mathrm{CN}(\mathrm{B})$-molecule reach equilibrium rotational distribution before emitting of the photons. Hence, the influence of high rotational distribution after excitation by collisions with argon metastables on the gas temperature determination by using $\mathrm{CN}$ molecular emission is also negligible.

\subsection{Simulation of electron velocity distribution function}

The electron velocity distribution function (EVDF) is determined on the basis of the emission of nitrogen molecule (equations 1-13). For this emission, the ground state nitrogen molecule can be excited by electron impact as well as by collision with argon metastables (equations 1-4). The ratio of emission intensity of $\mathrm{N}_{2}^{+}(\mathrm{B}-\mathrm{X})$ to the emission intensity of $\mathrm{N}_{2}(\mathrm{C}-\mathrm{B})$ depends on the EVDF. On this basis, the ratios of emission intensity of $\mathrm{N}_{2}{ }^{+}\left(\mathrm{B}^{2} \Sigma_{\mathrm{u}}{ }^{+}, v^{\prime}=0 \rightarrow \mathrm{X}^{2} \Sigma_{\mathrm{g}}{ }^{+}, v^{\prime \prime}=0\right)\left(I_{N_{2}^{+}(B-X)}\right)$ to the intensity of $\mathrm{N}_{2}(\mathrm{C}-\mathrm{B}, 0-0)$ $\left(I_{N_{2}(C-B)}\right)$ are calculated for various EVDFs by using the equations $(10,11)$. Finally, the actual EVDF is obtained by comparing the experimentally determined value of $I_{N_{2}^{+}(B-X)} / I_{N_{2}(C-B)}$ with the calculated values of $I_{N_{2}^{+}(B-X)} / I_{N_{2}(C-B)}$ for various EVDFs.

$$
\begin{aligned}
& N_{2}+e \stackrel{k_{N_{2}^{+}(B)}}{\longrightarrow} N_{2}^{+}(B)+2 e \\
& N_{2}+e \stackrel{k_{N_{2}(C)}}{\longrightarrow} N_{2}(C)+e \\
& N_{2}+A r_{m e t} \stackrel{k_{N_{2}(C)}^{A r_{m e t}}}{\longrightarrow} N_{2}(C)+A r \\
& \longrightarrow N_{2}(B)+A r \\
& A r+e \stackrel{k_{A r_{m e t}}}{\longrightarrow} A r_{\text {met }}+e \\
& A r_{m e t}+2 A r \stackrel{k_{q A r_{m e t}}^{2 A r}}{\longrightarrow} \text { products } \\
& A r_{m e t}+N_{2} \stackrel{k_{q A r_{m e t}}^{N_{2}}}{\longrightarrow} \text { products } \\
& \mathrm{Ar}_{\text {met }}+\mathrm{CH}_{4} \stackrel{k_{q A r_{m e t}}^{\mathrm{CH}_{4}}}{\longrightarrow} \text { products } \\
& A r_{\text {met }}+e \stackrel{k_{q A r_{m e t}}^{e}}{\longrightarrow} \text { products }
\end{aligned}
$$




$$
\begin{aligned}
& I_{N_{2}(C-B)}=\left(k_{N_{2}(C)}+K_{N_{2}(C)}^{A r_{m e t}}\right) \cdot n_{e} \cdot\left[N_{2}\right] \cdot Q_{N_{2}(C)} \cdot g_{f} \cdot V_{p} \cdot t_{f} \\
& \frac{I_{N_{2}^{+}(B-X)}}{I_{N_{2}(C-B)}}=\frac{Q_{N_{2}^{+}(B)}}{Q_{N_{2}(C)}} \cdot \frac{k_{N_{2}^{+}(B)}}{k_{N_{2}(C)}+K_{N_{2}(C)}^{A r_{m e t}}}
\end{aligned}
$$

where,

$$
\begin{gathered}
Q=\frac{A}{A+k_{q N_{2}}^{A r} \cdot[A r]} \\
K_{N_{2}(C)}^{A r_{m e t}}=\frac{[A r] \cdot k_{N_{2}(C)}^{A r_{m e t}} \cdot k_{A r_{m e t}} \cdot(B 1) \cdot(B 2)}{n_{e} \cdot k_{q A r_{m e t}}^{e}+[A r]^{2} \cdot k_{q A r_{m e t}}^{2 A r}+\left[N_{2}\right] \cdot k_{q A r_{m e t}}^{N_{2}}+\left[C H_{4}\right] \cdot k_{q A r_{m e t}}^{C H_{4}}}
\end{gathered}
$$

$k_{N_{2}^{+}(B)}$ and $k_{N_{2}(C)}$ - electron impact excitation rate constants of nitrogen molecule for the corresponding excited state

$k_{N_{2}(C)}^{A r_{m e t}}$ - rate constant for the formation of $\mathrm{N}_{2}(\mathrm{C})$ by collision of argon metastable $\left(2.80 \times 10^{-11} \mathrm{~cm}^{3} \cdot \mathrm{s}^{-1}\right)$ [23]

$k_{A r_{m e t}}$ - electron impact excitation rate constant for argon metastable formation

$k_{q N_{2}}^{A r}$ - rate constant for the quenching of the corresponding excited states of nitrogen during collision with argon (for $\mathrm{N}_{2}(\mathrm{C}) 8.00 \times 10^{-13} \mathrm{~cm}^{3} \cdot \mathrm{s}^{-1}[23]$; for $\mathrm{N}_{2}^{+}(\mathrm{B}) 2.00 \times 10^{-10} \mathrm{~cm}^{3} \cdot \mathrm{s}^{-1}[25]$ )

$k_{q A r_{m e t}}^{e}\left(2.00 \times 10^{-7} \mathrm{~cm}^{3} \cdot \mathrm{s}^{-1}[26]\right), k_{q A r_{m e t}}^{2 A r}\left(1.20 \times 10^{-32} \mathrm{~cm}^{3} \cdot \mathrm{s}^{-1}[27]\right), k_{q A r_{m e t}}^{N_{2}}\left(3.50 \times 10^{-11} \mathrm{~cm}^{3} \cdot \mathrm{s}^{-1}\right.$ [28]) and $k_{q A r_{m e t}}^{\mathrm{CH}_{4}}\left(5.50 \times 10^{-10} \mathrm{~cm}^{3} \cdot \mathrm{s}^{-1}\right.$ [29]) - rate constants for quenching of argon metastable during collision with electron, argon, nitrogen and methane, respectively

$A$ - Einstein coefficient for spontaneous emission $\left(2.38 \times 10^{7} \mathrm{~s}^{-1}\right.$ for $\mathrm{N}_{2}(\mathrm{C})$ [30]; $1.52 \times 10^{7} \mathrm{~s}^{-1}$ for $\mathrm{N}_{2}^{+}(\mathrm{B})$ [31])

$B 1$ - branching factor for $(3)$ (value $=0.787)[32]$

$B 2$ - branching factor for $N_{2}(C-B, 0-0)$ transition by emission from $N_{2}(C, 0)($ value $=0.5)$ [33]

$n_{e}$ - density of electron $\left(\mathrm{cm}^{-3}\right)$

$[A r]$ - density of argon $\left(\mathrm{cm}^{-3}\right)$

$\left[N_{2}\right]$ - density of nitrogen $\left(\mathrm{cm}^{-3}\right)$

$\left[\mathrm{CH}_{4}\right]$ - density of methane $\left(\mathrm{cm}^{-3}\right)$

$V_{p}$ - observed volume of plasma $\left(\mathrm{cm}^{3}\right)$

$g_{f}$ - geometrical factor for the spectrum measurement

$t_{f}$ - value of fraction of time, in which plasma is active 
The equations (10-13) are derived on the basis that the population of $\mathrm{N}_{2}{ }^{+}(\mathrm{B})$ from the ground state ion $\mathrm{N}_{2}^{+}(X)$ is negligible compared to the one from $\mathrm{N}_{2}(X)$. This is because the concentration of $\mathrm{N}_{2}^{+}(X)$ is negligible compared to the concentration of $\mathrm{N}_{2}(X)$ in the cases we studied. For the generation of $\mathrm{N}_{2}(C)$, only direct electron impact excitation from the ground state of nitrogen molecule $\mathrm{N}_{2}(X)$ and the excitation during collision with argon metastable are considered [28,34-36]. Other possible mechanism of generation of $\mathrm{N}_{2}(\mathrm{C})$ by 'pooling' reactions of two metastables $\mathrm{N}_{2}(\mathrm{~A})$ [37] is negligible because of relatively low density of metastables $\mathrm{N}_{2}(\mathrm{~A})$. Quenching of $\mathrm{N}_{2}(\mathrm{C})$ and $\mathrm{N}_{2}{ }^{+}(\mathrm{B})$ by argon is considered [23,25,36]. However, quenching of $\mathrm{N}_{2}(\mathrm{C})$ and $\mathrm{N}_{2}^{+}(\mathrm{B})$ by nitrogen and methane is neglected because of low concentration of these admixtures [38].

For the calculation of rate constants $k_{N_{2}^{+}(B)}$ and $k_{N_{2}(C)}$ for a particular EVDF under our experimental conditions, the following methodology is used.

The EVDF is simulated for our experimental conditions by numerical solution of the Boltzmann equation and varied electric field applying the program code "EEDF" developed by Napartovich et al [39]. In this simulation, "local" approximation is applied, which is valid for atmospheric pressure. This EVDF is normalized to fulfill the equation (14):

$$
4 \pi \sqrt{2} \int_{0}^{\infty} f_{v}(E) \cdot \sqrt{E} \mathrm{~d} E=1
$$

By using this normalized EVDF and the known collisional cross section $\sigma_{e x c}\left(\mathrm{~cm}^{2}\right)$ for electron and nitrogen for the corresponding emission excitation [40], we calculate the rate constant $k\left(\mathrm{~cm}^{3} \cdot \mathrm{s}^{-1}\right)$ for electron impact excitation of $\mathrm{N}_{2}(\mathrm{C}-\mathrm{B}, 0-0)$ and $\mathrm{N}_{2}{ }^{+}(\mathrm{B}-\mathrm{X}, 0-0)$ emissions by using the equation (15):

$$
k=4 \pi \sqrt{2} \int_{0}^{\infty} f_{v}(E) \cdot \sqrt{\frac{2 C}{m_{e}}} \cdot E \cdot \sigma_{e x c}(E) \mathrm{d} E,
$$

where $m_{\mathrm{e}}$ is the mass of electron $(\mathrm{g}), E$ is the kinetic energy of electrons $(\mathrm{eV})$ and $C=1.602 \times 10^{-12} \mathrm{erg}$. $\mathrm{eV}^{-1}$.

From these calculated rate constants, the intensities of nitrogen emissions are calculated for various EVDFs. By comparing the ratio of these emission intensities with measured one, the actual EVDF and its corresponding reduced electric field are determined.

\subsection{Determination of electron density}

From the measured absolute intensity of $\mathrm{N}_{2}(\mathrm{C}-\mathrm{B}, 0-0)$ emission $\left(\right.$ phot $\left.^{\cdot} \mathrm{cm}^{-3} \cdot \mathrm{s}^{-1}\right)$, the electron impact excitation rate constant $k_{N_{2}(C)}$ for $\mathrm{N}_{2}(\mathrm{C}-\mathrm{B}, 0-0)$ emission, the plasma volume $\left(V_{p}\right.$ in $\left.\mathrm{cm}^{-3}\right)$, value of fraction of time in which plasma is active $\left(t_{f}\right)$, contributions of the quenching of $\mathrm{N}_{2}(\mathrm{C})$ by Ar, contribution of excitation of $\mathrm{N}_{2}(\mathrm{C})$ by argon metastable, and the geometrical conditions during the measurement of emission spectrum $\left(g_{f}\right)$, the electron density $\left(n_{e}\right.$ in $\left.\mathrm{cm}^{-3}\right)$ is determined by using the equation (16): 


$$
n_{e}=\frac{I_{N_{2}(C-B)}}{Q_{N_{2}(C)} \cdot\left[N_{2}\right] \cdot V_{p} \cdot\left(k_{N_{2}(C)}+K_{N_{2}(C)}^{A r_{m e t}}\right) \cdot t_{f} \cdot g_{f}}
$$

All the measurements with our emission spectrometer are space and time averaged. However, the plasma parameters during the discharge are spatially and temporally non-uniform [41]. In order to find out the influence of this non-uniformity of the plasma parameters on the reliability of measurements obtained using our spectrometer, we have simulated the total emission spectrum of two plasma regions of equal volume observed by our spectrometer simultaneously. Very different plasma conditions are assumed for these two regions. The composition of argon, nitrogen and methane in the gas mixture corresponding to the positive corona discharge is used for the simulations. By using the total emission spectrum of nitrogen simulated for these two regions with different plasma parameters, the average plasma parameters are calculated for our optical emission spectroscopic (OES) diagnostics. By using these averaged plasma parameters, the rate of methane dissociation is calculated. This value is compared with the value of the rate of methane dissociation calculated for these two regions.

For this purpose, the reduced electric field of $300 \mathrm{Td}$ is assumed for the first region while $3000 \mathrm{Td}$ for the second region. Electron density values are assumed as $2.00 \times 10^{11}$ and $3.00 \times 10^{11}\left(\mathrm{in}^{-3}\right)$ for the first and the second regions, respectively. In these plasma conditions, the intensity of $\mathrm{N}_{2}(\mathrm{C}-\mathrm{B}, 0-0)$, which is used for electron density determination, is equal in both regions. On this basis, we have calculated total intensities of emission of nitrogen for the combination of these two regions, in the way our spectrometer would have observed. From these calculated values of intensities, the averaged values of electric field and electron density are calculated as $2040 \mathrm{Td}$ and $4.20 \times 10^{11} \mathrm{~cm}^{-3}$, respectively. The ultimate aim for determination of the plasma parameters is to obtain the dissociation rate of methane. Hence, by using these averaged values of electron density and the reduced electric field, the rate of methane dissociation is calculated for this combined region. In a similar way, the dissociation rate of methane is calculated for these two regions separately on the basis of the emission spectra simulated for a spatially resolved measurement. The sum of these two values obtained for the spatially resolved measurement, is compared with the value of methane dissociation rate for the combined region calculated using the averaged plasma parameters for the spatially averaged measurement. In this case, there is less than $1 \%$ deviation in the rate of methane dissociation in using averaged plasma parameters.

We did similar calculation by assuming very different electron density values for these two regions, as $5.00 \times 10^{13} \mathrm{~cm}^{-3}$ and $3.00 \times 10^{11}\left(\mathrm{~cm}^{-3}\right)$ for the first $(\mathrm{E} / \mathrm{N}, 300 \mathrm{Td})$ and the second $(\mathrm{E} / \mathrm{N}, 3000 \mathrm{Td})$ regions, respectively. For these values of electron density and the electric field, the intensity of $\mathrm{N}_{2}{ }^{+}(\mathrm{B}-\mathrm{X}, 0-0)$ for these two regions is equal. In this case, there is $9 \%$ deviation in the value of rate of methane dissociation by using spatially averaged plasma parameters.

The low time resolution in OES diagnostics causes an error in electron density determination because of the error in the time factor. The inverse of the same time factor is used for determination of the rate of methane dissociation from electron density. Hence, the error in the time factor during electron density determination will be canceled during determination of the rate of methane dissociation. Hence, despite the possible deviation of the averaged plasma parameters determined using our OES diagnostics, from the real spatial and temporal distribution of plasma parameters (EVDF and electron density), the dissociation rate of methane molecules obtained using the averaged plasma parameters is reliable. 


\section{Results and Discussion}

\subsection{Different modes of discharge}

The pulsed corona discharge is ignited in the mixture of argon, methane and nitrogen gases. The long filament of plasma generated along the axis of the tube during this discharge has a diameter varying from 0.5 to $0.85 \mathrm{~mm}$, as shown in figure 3 . Depending on the quantity of the admixture $\mathrm{CH}_{4}$ and/or $\mathrm{N}_{2}$ in the plasma forming gas (Ar), the positive as well as the negative corona discharges can be ignited (figure 4) [14]. When the quantity of admixtures is low ( $\mathrm{Ar}, 99.82 \% ; \mathrm{N}_{2}, 0.14 \% ; \mathrm{CH}_{4}, 0.04 \%$ ), the pulsed negative corona discharge is ignited. On the other hand, the positive corona discharge is ignited at the higher concentration of admixtures ( $\left.\mathrm{Ar}, 99.74 \% ; \mathrm{N}_{2}, 0.14 \% ; \mathrm{CH}_{4}, 0.12 \%\right)$. This fact is confirmed by ignition of different modes of corona discharge at different quantity of only nitrogen admixture in argon as well as only methane admixture in argon. The duration of the negative corona discharge (around $260 \mathrm{~ns}$ ) is higher than that of the positive corona discharge (around $160 \mathrm{~ns}$ ).

Tungsten electrode

Grounded copper

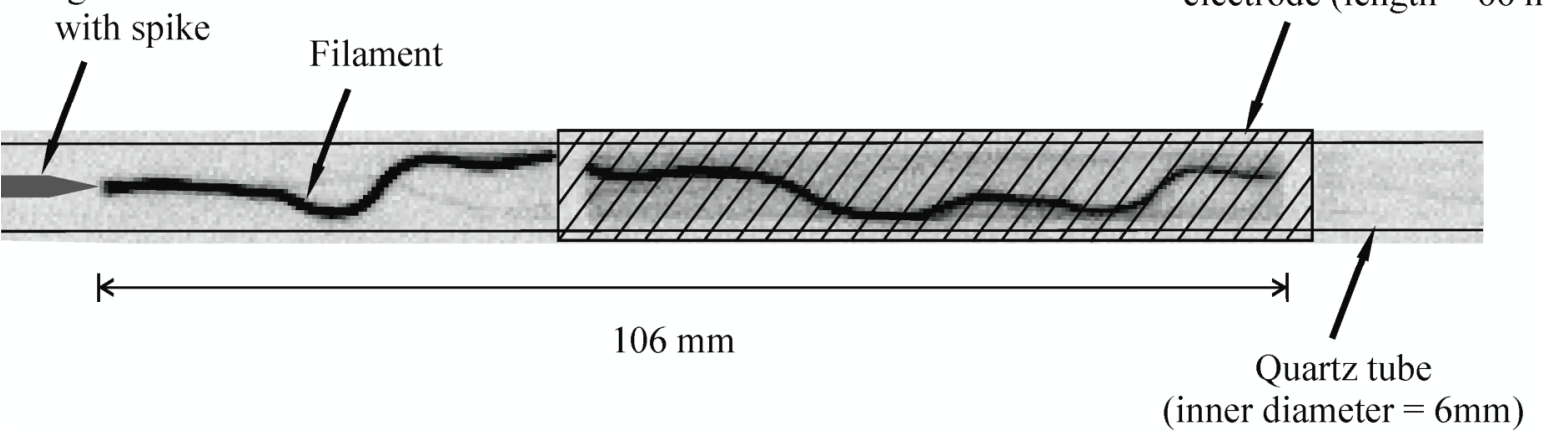

Figure 3. Inverted image of the filament generated inside the quartz tube during the pulsed negative corona discharge in the gas composition of $\mathrm{Ar}, 99.82 \% ; \mathrm{N}_{2}, 0.14 \% ; \mathrm{CH}_{4}, 0.04 \%$, at the total gas flow rate of $2170 \mathrm{sccm}$ (the grounded electrode region is shaded, and the filament in this region is viewed through the void in this electrode); PCO sensitive camera exposure time, $40 \mu \mathrm{s}$.

In the case of the negative corona discharge, multiplying electrons of avalanche propagate from the tungsten cathode into the region of progressively weak field. Avalanche propagation occurs only up to the region where the effective ionization coefficient, $\alpha(E)-a$, is positive (where $\alpha(E)$ - first Townsend coefficient and $a$-attachment coefficient). Both coefficients $\alpha(E)$ and $a$ depend on the gas components. By admixing of molecular gases to rare gas, the ionization coefficient $\alpha(E)$ is decreased because of loss of electron energy by inelastic collisions with molecules. At the same time, the attachment coefficient $a$ is increased because of large attachment cross-sections of molecular ions. Therefore, by admixing of molecular gases, higher applied voltage is required for propagation of electron avalanches in the ignition of negative corona. Hence, although the voltage pulse begins with negative polarity, the negative corona is not ignited in argon with high quantities of molecular admixtures ( $\left.\mathrm{Ar}, 99.74 \% ; \mathrm{N}_{2}, 0.14 \% ; \mathrm{CH}_{4}, 0.12 \%\right)$. It is ignited only when there is no or a small quantity of molecular admixtures in argon. Compared to the negative corona, positive corona requires lower applied voltage for ignition, because in this case, the electron avalanches propagate towards the streamer head from outside into the region of progressively stronger electric field. Hence, with high quantities of molecular admixtures in argon, the filament is ignited only as the positive corona during first positive polarity of the voltage pulse. 

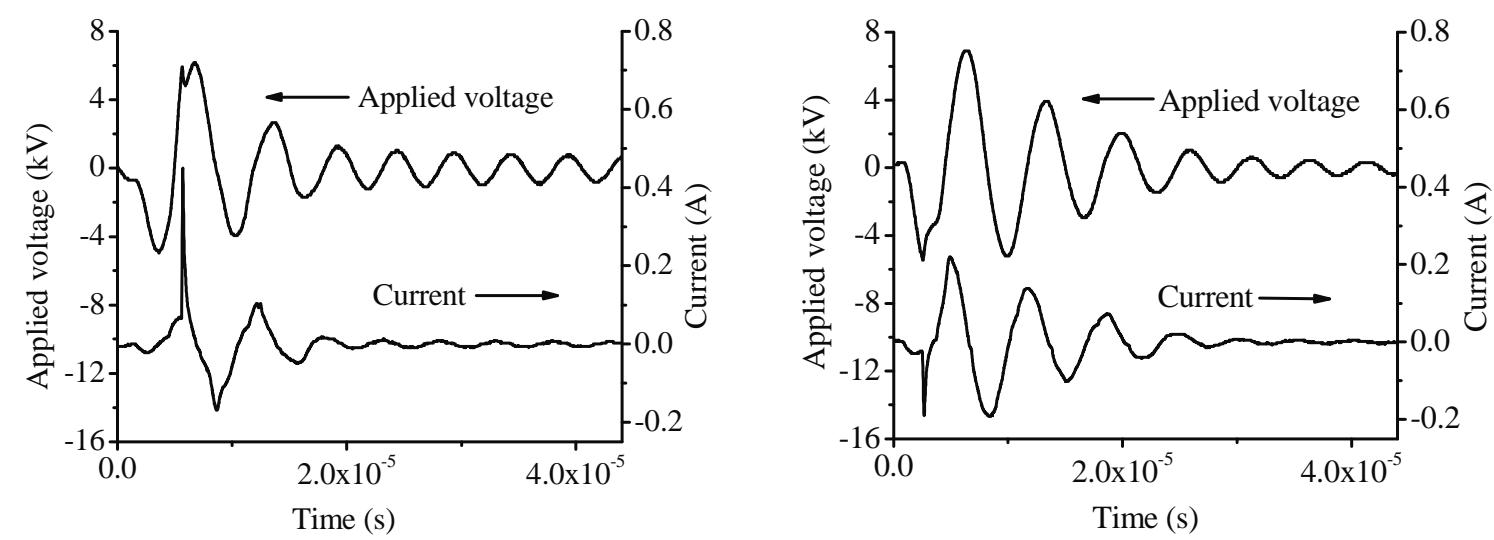

Figure 4. Current and voltage profiles during the pulsed positive corona discharge (left; Ar, 99.74\%; $\mathrm{N}_{2}, 0.14 \%$; $\mathrm{CH}_{4}, 0.12 \%$; total gas flow rate, $2170 \mathrm{sccm}$ ) as well as during the pulsed negative corona discharge (right; Ar, $99.82 \% ; \mathrm{N}_{2}, 0.14 \% ; \mathrm{CH}_{4}, 0.04 \%$; total gas flow rate, $\left.2170 \mathrm{sccm}\right)$. The pulse frequency is $22 \mathrm{kHz}$. The voltage frequency of each pulse sequence is around $200 \mathrm{kHz}$.

The region between the spike and the surface of the tube covered by the grounded electrode, is conductive through the filament after discharge ignition has taken place. This causes the high displacement current (figure 4), and also influences the delay in ignition of the next corona discharge after previous breakdown because of low electric field in the conductive layer. Therefore, only one corona discharge is ignited for each high voltage pulse sequence.

\subsection{Gas temperature}

Determination of gas temperature is very important not only to obtain the plasma parameters, and to simulate the chemical kinetics, but also to get to know the feasibility of using this microplasma jet for doing film coating on inner surface of thermolabile plastic tubes. Hence, the gas temperature is determined during both modes of discharge at various places along the axis of the tube, which is shown in figure 5 . The tube is divided into two zones as, 1. the region in between the tungsten electrode and the copper electrode (spike region), and 2. region of the tube, which is covered by the copper electrode (grounded region).

The neutral gas is heated during collision with positive ions, which are accelerated by the electric field especially near the spike with negative polarity, and a head of the streamer. In addition to this, gas near the spike is heated during heat transfer from the electrode heated during ions bombardment. Hence, the gas temperature during the negative corona discharge is higher than the one during the positive corona discharge, especially in the spike region. In both cases, gas exhibits high temperature at close to left end of the grounded electrode. From this point, the gas temperature decreases as the distance increases from the spike along the axis of the tube. The reason for this behavior in temperature is under investigation. 


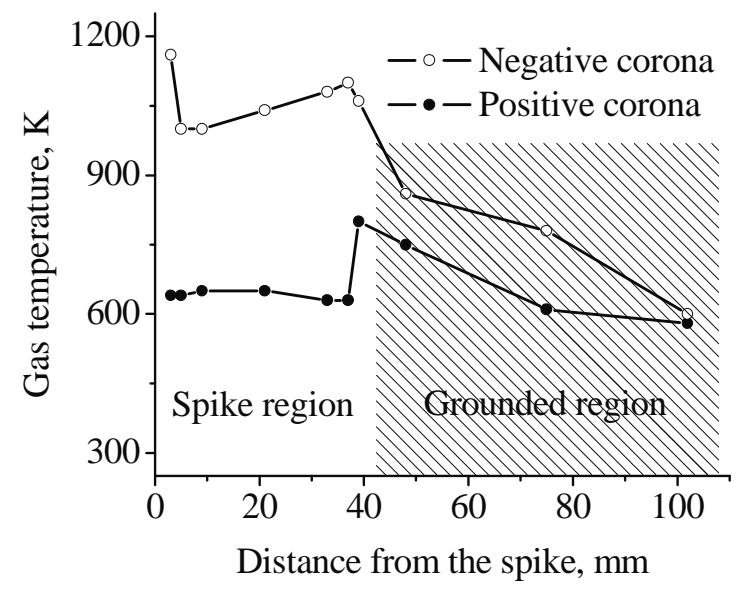

Figure 5. Gas temperature along the axis of the tube during the pulsed negative corona discharge (Ar, 99.82\%; $\mathrm{N}_{2}$, $0.14 \% ; \mathrm{CH}_{4}, 0.04 \%$; total gas flow rate, $2170 \mathrm{sccm}$ ) as well as during the pulsed positive corona discharge (Ar, $99.74 \% ; \mathrm{N}_{2}, 0.14 \% ; \mathrm{CH}_{4}, 0.12 \%$; total gas flow rate, $\left.2170 \mathrm{sccm}\right)$.

Although the gas temperature in the plasma filament is high (figure 5), duration of the corona discharge pulses is short of about 160-260 ns (see section 3.1). Therefore, the actual temperature of the tube will be much lower than the gas temperature in the plasma filament. To study the heating of treated surface of the tube during film deposition, the equation of heat conductivity has to be solved, which will be done in the future.

\subsection{Reduced electric field and EVDF}

The reduced electric field during the positive corona discharge is higher than that during the negative corona discharge (figure 6). This is because of high electric field near the head of the streamer during the propagation of the positive corona discharge. In both cases, it has low value in the grounded region, except midpoint in this region during the positive corona discharge. The behavior of reduced electric field near the edges of the grounded electrode for both modes of corona discharge is not clear now. 


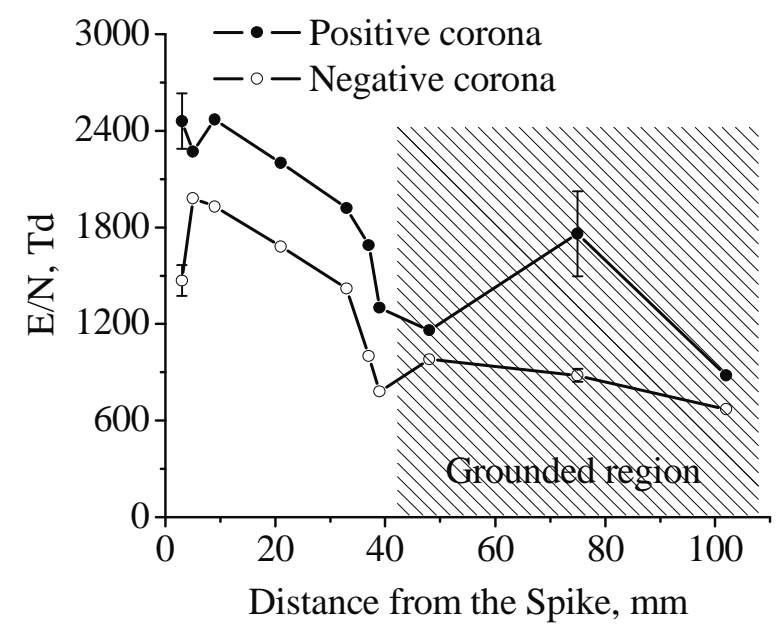

Figure 6. Variation of the reduced electric field along the axis of the tube during the pulsed positive corona discharge (Ar, 99.74\%; $\mathrm{N}_{2}, 0.14 \% ; \mathrm{CH}_{4}, 0.12 \%$; total gas flow rate, $2170 \mathrm{sccm}$ ) as well as during the pulsed negative corona discharge (Ar, $99.82 \% ; \mathrm{N}_{2}, 0.14 \% ; \mathrm{CH}_{4}, 0.04 \%$; total gas flow rate, $\left.2170 \mathrm{sccm}\right)$.

The difference in the reduced electric field between two modes of pulsed corona discharge influences their EVDF as shown in figure 7.

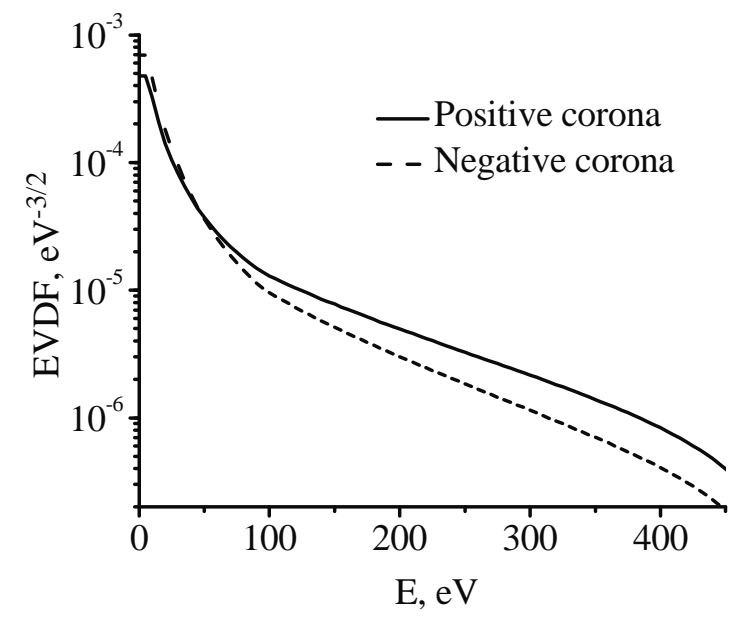

Figure 7. EVDFs determined for the reduced electric field inside the tube at $21 \mathrm{~mm}$ from spike for the pulsed positive corona discharge ( $\mathrm{Ar}, 99.74 \% ; \mathrm{N}_{2}, 0.14 \% ; \mathrm{CH}_{4}, 0.12 \%$; total gas flow rate, $2170 \mathrm{sccm}$ ) as well as for the pulsed negative corona discharge (Ar, 99.82\%; $\mathrm{N}_{2}, 0.14 \% ; \mathrm{CH}_{4}, 0.04 \%$; total gas flow rate, $2170 \mathrm{sccm}$ ).

\subsection{Electron Density}

The electron density is almost constant in most part of the spike region during the negative corona discharge as well as during the positive corona discharge (figure 8). However, it increases by a factor of about three at the edge of the grounded region. Spatial distribution of electron density during the pulsed 
positive corona has a trend opposite to that of the electric field. It exhibits a similar behavior in the spike region during the pulsed negative corona discharge. However, in the grounded region, the electron density increases while the electric field remains constant (see figure 6). Also, the filament propagates far outside of the grounded region during the pulsed negative corona discharge.

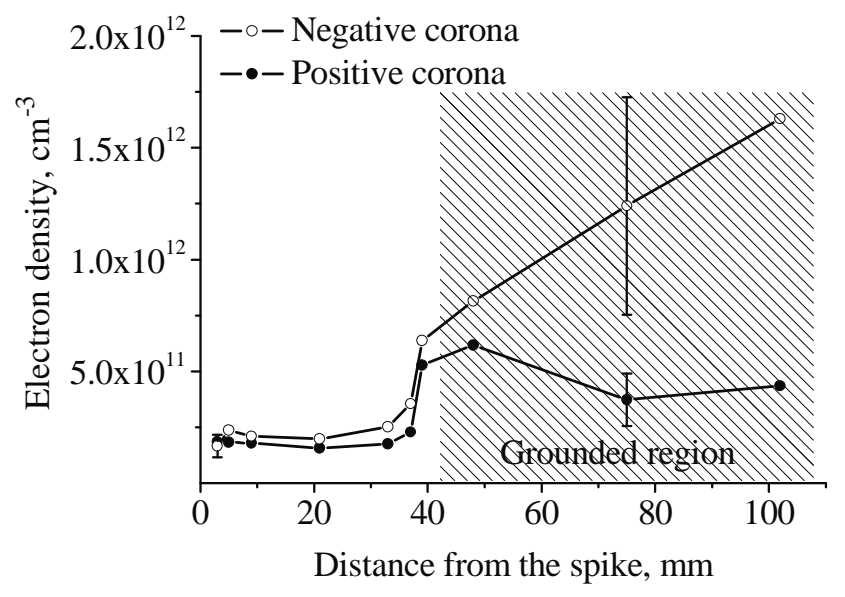

Figure 8. Electron density profile along the axis of the tube during the pulsed negative corona discharge (Ar, $99.82 \% ; \mathrm{N}_{2}, 0.14 \% ; \mathrm{CH}_{4}, 0.04 \%$; total gas flow rate, $2170 \mathrm{sccm}$ ) as well as during the pulsed positive corona discharge (Ar, 99.74\%; $\mathrm{N}_{2}, 0.14 \% ; \mathrm{CH}_{4}, 0.12 \%$; total gas flow rate, $2170 \mathrm{sccm}$ ).

\subsection{Precursor dissociation}

The rate of methane dissociation $\left(R_{\mathrm{CH}_{4}}\right)$ is determined, from the known value of cross-section of electron impact dissociation of methane [42], determined EVDF, time fraction of active plasma $\left(t_{f}\right)$, and densities of methane and electron, by using the equation (16):

$$
R_{C H_{4}}=n_{e} \cdot\left[C H_{4}\right] \cdot t_{f} \cdot 4 \pi \sqrt{2} \int_{0}^{\infty} f_{v}(E) \cdot \sqrt{\frac{2 C}{m_{e}}} \cdot E \cdot \sigma_{d i s s}(E) \mathrm{d} E
$$

The trend of precursor dissociation rate along the axis of the tube during both modes of discharge is shown in figure 9. Dissociation rate is more or less constant along the axis of the tube in the spike region. During the pulsed positive corona discharge, although electron density is lower in this region, the concentration of methane and the rate constant of methane dissociation are higher than those during the pulsed negative corona discharge. Hence, the dissociation rate of methane precursor in this region during the positive corona discharge is higher than the one during the negative corona discharge. The high rate constant for methane dissociation during the positive corona is due to the high electric field near the streamer head. In both cases, the dissociation rate in the spike region is less than that in the grounded region. 


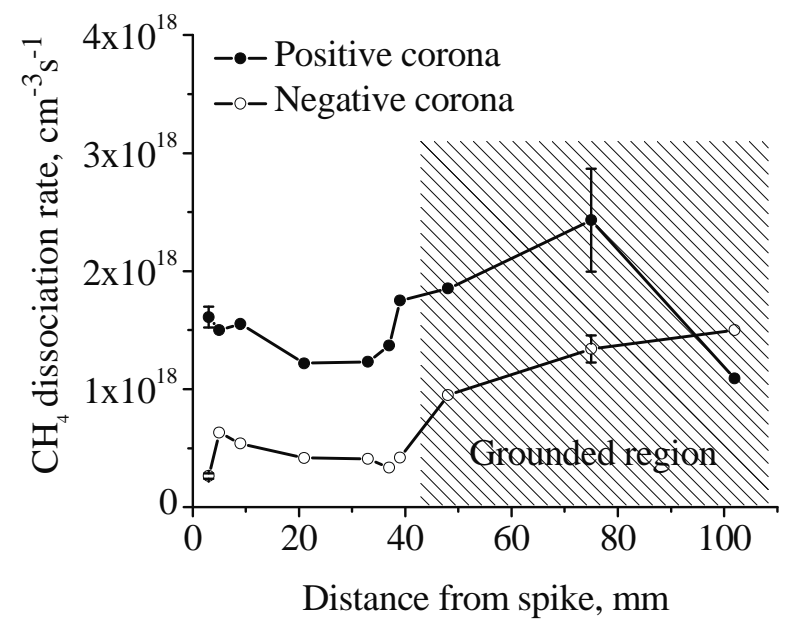

Figure 9. Variation in the rate of dissociation of methane along the axis of the tube during the pulsed positive corona discharge (Ar, 99.74\%; $\mathrm{N}_{2}, 0.14 \% ; \mathrm{CH}_{4}, 0.12 \%$; total gas flow rate, $2170 \mathrm{sccm}$ ) as well as during the pulsed negative corona discharge $\left(\mathrm{Ar}, 99.82 \% ; \mathrm{N}_{2}, 0.14 \% ; \mathrm{CH}_{4}, 0.04 \%\right.$; total gas flow rate, $\left.2170 \mathrm{sccm}\right)$.

The actual number of methane molecules dissociated in $1 \mathrm{~mm}$ length of the filament, at various places along the axis of the tube, is determined from the volume of $1 \mathrm{~mm}$ length of the filament and it is shown in figure 10. It shows that the quantity of methane dissociated is constant in most part of the spike region, favoring a uniform film deposition in this region. However, it increases in the grounded region because of the increase in the values of the plasma parameters, and becomes non-homogeneous in the grounded region. Hence, our forthcoming investigation will mainly be focused on reducing this difference in the plasma parameters in various regions along the axis of the tube.

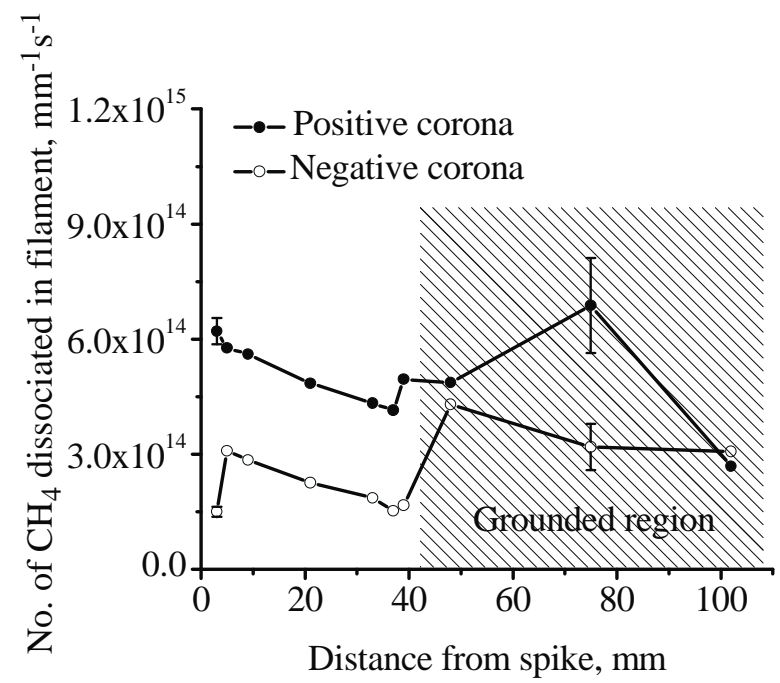

Figure 10. Profiles of quantity of methane dissociated along the axis of the tube during the pulsed positive corona discharge (Ar, 99.74\%; $\mathrm{N}_{2}, 0.14 \% ; \mathrm{CH}_{4}, 0.12 \%$; total gas flow rate, $2170 \mathrm{sccm}$ ) as well as during the pulsed negative corona discharge ( $\mathrm{Ar}, 99.82 \% ; \mathrm{N}_{2}, 0.14 \% ; \mathrm{CH}_{4}, 0.04 \%$; total gas flow rate, $\left.2170 \mathrm{sccm}\right)$. 


\subsection{Radicals production}

The emission spectra measured using the echelle spectrometer during the discharge clearly shows the presence of $\mathrm{C}, \mathrm{C}_{2}$ and $\mathrm{CH}$ through their characteristic emission [43-45] as shown in figure 11. It also confirms the dissociation of methane precursor and the consequent formation of the active species for polymerization.

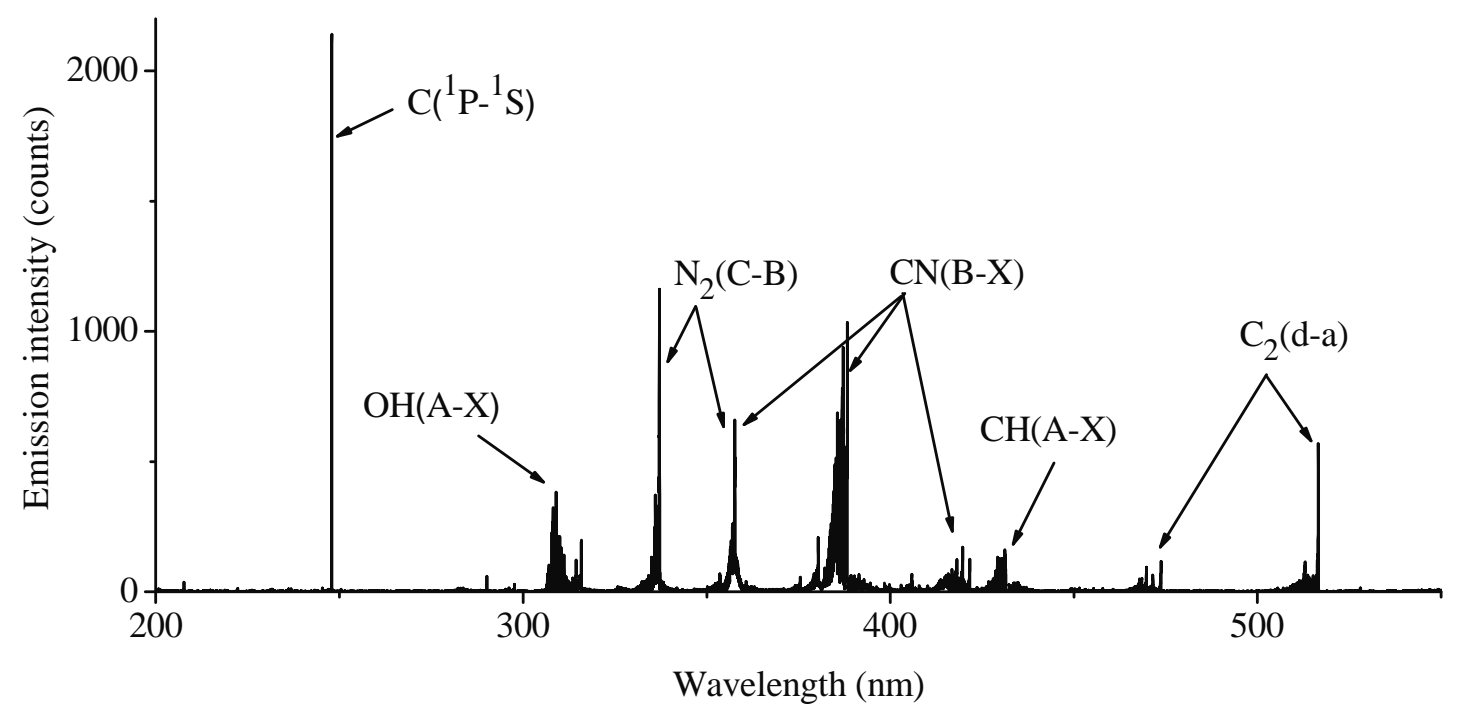

Figure 11. Emission spectrum measured at $48 \mathrm{~mm}$ from the spike in the grounded region using echelle spectrometer during the pulsed positive corona discharge ignited at total gas flow rate of $2170 \mathrm{sccm}\left(\mathrm{Ar}, 99.74 \% ; \mathrm{N}_{2}, 0.14 \% ; \mathrm{CH}_{4}\right.$, $0.12 \%)$.

\subsection{Deposited film characterization}

The initial characterization of films deposited during these modes of discharge by FTIR spectroscopy in the transmittance mode indicates the presence of aliphatic $\mathrm{C}-\mathrm{H}$ groups in the film through their characteristic absorption. The film obtained during the positive corona exhibits peaks at 2958, 2932 and $2872 \mathrm{~cm}^{-1}$ corresponding to $\mathrm{CH}_{3}$ asymmetric stretch, $\mathrm{CH}_{2}$ asymmetric stretch and $\mathrm{CH}_{2}$ symmetric stretch, respectively [46-49], indicating the higher composition of hydrogen in the hydrocarbon film (figure 12). For the film obtained during the negative corona discharge, the presence of mainly two peaks at 2918 and $2849 \mathrm{~cm}^{-1}$ in the aliphatic C-H stretching region corresponding to $\mathrm{CH}_{2}$ asymmetric stretch and $\mathrm{CH}_{2}$ symmetric stretch, respectively, is indicating the presence of long hydrocarbon polymeric chain in the film [50]. High absorption intensities for the film obtained during the positive corona discharge indicates the presence of thick film and hence, the high growth rate of the film compared to the one during the negative corona discharge. Although the quantity of methane molecules dissociated during both discharge modes is comparable, this strong difference in growth rate is due to the difference in the chemical kinetics of film growth process during these two modes of discharge. These differences in the number of peaks, the intensity and the absorption wave number for the films obtained during the positive as well as the negative corona discharges indicate that the different nature of the films are deposited during different modes of 
discharge. Further analysis of the films deposited during different modes of discharge at various regions along the axis of the tube is under progress. In future, the fluxes of $\mathrm{C}_{\mathrm{x}} \mathrm{H}_{\mathrm{y}}$ molecules towards the inner surface of the tube will be simulated by solving the equations for heat conductivity, diffusion and chemical kinetics from the determined values of gas temperature, averaged plasma parameters and the rate of methane dissociation.

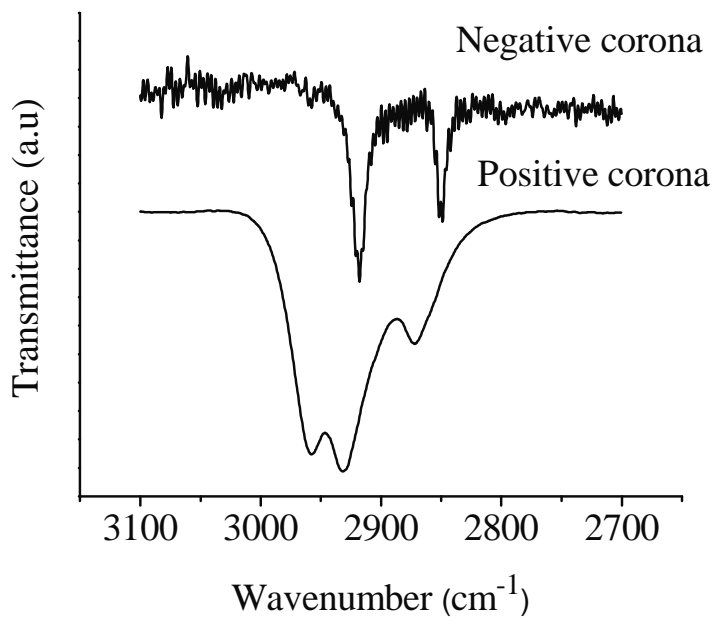

Figure 12. FTIR spectra of the films in the grounded region of the tube obtained during the pulsed negative corona discharge (Ar, 99.82\%; $\mathrm{N}_{2}, 0.14 \% ; \mathrm{CH}_{4}, 0.04 \%$; total gas flow rate, $2170 \mathrm{sccm}$ ) as well as during the pulsed positive corona discharge (Ar, 99.74\%; $\mathrm{N}_{2}, 0.14 \% ; \mathrm{CH}_{4}, 0.12 \%$; total gas flow rate, $\left.2170 \mathrm{sccm}\right)$. For ease of comparison, the spectrum of the film obtained during the negative corona discharge is shifted above.

\section{Summary and Outlook}

The microplasma jet has been constructed to produce the long filament of plasma inside the tube in argon with methane (precursor) and nitrogen admixtures. The negative as well as the positive pulsed corona discharges are ignited by varying the quantity of admixtures (precursor/nitrogen) in the plasma forming gas (Ar). The EVDF is obtained on the basis of the distribution among the population of $\mathrm{N}_{2}(\mathrm{C})$ and $\mathrm{N}_{2}{ }^{+}$(B). The gas temperature during the positive corona discharge is lower than the one during the negative corona discharge. However, the reduced electric field during the positive corona discharge along the axis of the tube is higher than the one during the negative corona discharge. Although the electron density is lower during the positive corona discharge, the concentration of methane and the rate constant of methane dissociation are higher than those during the negative corona discharge. Hence, the dissociation rate of methane precursor during the positive corona discharge is higher than the one during the negative corona discharge. The production of active species like, $\mathrm{C}, \mathrm{C}_{2}, \mathrm{CH}$, etc. for the polymerization is observed through their characteristic emissions. The FTIR spectra of the films indicate the presence of different kinds of films obtained during the different modes of discharge because of different chemical kinetics and film growth rate during these different modes of discharge. Further analysis of the films obtained in different regions of the tube during different modes of discharge is under progress. Although at this moment, the system is not fully optimized for uniform film coating for long distance, in future, input parameters like, applied voltage, pulse frequency, duty cycle, composition of gas mixture and flow rate will be optimized in order to get a better quality film for long distance. 


\section{Acknowledgement}

This work is supported by the 'Deutsche Forschungsgemeinschaft' (DFG) within the frame of the research group 'FOR1123 - Physics of Microplasmas'.

\section{References}

[1] Babukutty Y, Prat R, Endo K, Kogoma M, Okazaki S and Kodama M 1999 Langmuir 157055

[2] Prat R, Koh Y J, Babukutty Y, Kogoma M, Okazaki S and Kodama M 2000 Polymer 417355

[3] Yoshiki H, Abe K and Mitsui T 2006 Thin Solid Films 5151394

[4] Wang L, Huang L, Wang Y, Xie Z and Wang X 2008 Surf. Coat. Technol. 2023391

[5] Hytry R, Möller W and Wilhelm R 1994 Appl. Phys. Lett. 643401

[6] Fujiyama H 2000 Surf. Coat. Technol. 131278

[7] Deilmann M, Halfmann H, Steves S, Bibinov N and Awakowicz P 2009 Plasma Process. Polym. 6 S695

[8] Deilmann M, Theiß S and Awakowicz P 2008 Surf. Coat. Technol. 2021911

[9] Yoshiki H and Mitsui T 2008 Surf. Coat. Technol. 2025266

[10] Yoshiki H and Saito T 2008 J. Vac. Sci. Technol. A 26338

[11] Ağıral A, Lefferts L and Gardeniers J G E 2009 IEEE Trans. Plasma Sci. 37985

[12] Hytry R, Möller W, Wilhelm R and Keudell A v 1993 J. Vac. Sci. Technol. A 112508

[13] Foest R, Kindel E, Lange H, Ohl A, Stieber M and Weltmann K -D 2007 Contrib. Plasma Phys. 47 119

[14] Veldhuizen E M v, Rutgers W R and Ebert U 2002 Int. Symp. HAKONE VIII Pühajärve, Estonia p. 33

[15] Bibinov N, Halfmann H, Awakowicz P and Wiesemann K 2007 Meas. Sci. Technol. 181327

[16] Murugavel R and Pothiraja R 2003 New J. Chem. 27968

[17] Pothiraja R, Sathiyendiran M, Butcher R J and Murugavel R 2005 Inorg. Chem. 446314

[18] Bibinov N K, Fateev A A and Wiesemann K 2001 J. Phys. D: Appl. Phys. 341819

[19] Luque J and Crosley D R 1999 "LIFBASE: Database and spectral simulation (version 1.5)", SRI International Report MP 99-009

[20] Nguyen T D and Sadeghi N 1983 Chem. Phys. 7941

[21] Urisu T and Kuchitsu K 1973 Chem. Phys. Lett. 18337

[22] Belikov A E, Burshtein A I, Dolqushev S V, Storojev A V, Strekalov M L, Sukhinin G I and Sharafutdinov R G 1988 Rate constants and relaxation time of nitrogen in argon, Preprint (Novosibirsk: Institute of Thermal Physics, Russian Academy of Science) (in Russian)

[23] Polak-Dingels P and Djeu N 1983 J. Appl. Phys. 546818

[24] Duewer W H, Coxon J A and Setser D W 1972 J. Chem. Phys. 564355 
[25] Tellinghuisen J B, Winkler C A, Freeman C G, McEwan M J and Phillips L F 1972 J. Chem. Soc., Faraday Trans. 268833

[26] Ivanov V A and Makasyuk I V 1990 Opt. Spectrosc. (USSR) 69308

[27] Kolts J H and Setser D W 1978 J Chem. Phys. 684848

[28] Kolts J H, Brashears H C and Setser D W 1977 J. Chem. Phys. 672931

[29] Velazco J E, Kolts J H and Setser D. W 1978 J. Chem Phys. 694357

[30] Pancheshnyi S V, Starikovskaia S M and Starikovskii A Yu 2000 Chem. Phys. 262349

[31] Dilecce G, Ambrico P F and Benedictis S De 2010 J. Phys. D: Appl. Phys. 43195201

[32] Zhiglinski A G 1994 Handbook of Rate Constants of Process of Atoms, Electrons and Photons (St. Petersburg: St. Petersburg university press) (in Russian)

[33] Laux C O and Kruger C H 1992 J. Quant. Spectrosc. Radiant. Transfer 489

[34] Sadeghi N, Cheaib M and Setser D W 1989 J. Chem. Phys. 90219

[35] Sadeghi N and Setser D W 1981 Chem. Phys. Lett. 8244

[36] Touzeau M and Pagnon D 1978 Chem. Phys. Lett. 53355

[37] Herron J T 1999 J. Phys. Chem. Ref. Data 281453

[38] Legrand J -C, Diamy A -M, Hrach R and Hrachová V 2001 Advances in Plasma Physics Research (vol 1) ed S Boriotti and D Dennis (New York: Nova) p. 10

[39] Stefanović I, Bibinov N K, Deryugin A A, Vinogradov I P, Napartovich A P and Wiesemann K 2001 Plasma Sources Sci. Technol. 10406

[40] Itikawa Y 2006 J. Phys. Chem. Ref. Data 3531

[41] Veldhuizen E M v, Nijdam S, Luque A, Brau F and Ebert U 2009 Eur. Phys. J. Appl. Phys. 47 22811

[42] García G and Manero F 1998 Phys. Rev. A 571069

[43] Chingsungnoen A, Wilson J I B, Amornkitbamrung V, Thomas C and Burinprakhon T 2007 Plasma Sources Sci. Technol. 16434

[44] Yanguas-Gil A, Hueso J L, Cotrino J, Caballero A and González-Elipe A R 2004 Appl. Phys. Lett. 854004

[45] Acquaviva S and De Giorgi M L 2002 Appl. Surf. Sci. 186329

[46] Kim J -H, Liu G and Kim S H 2006 J. Mater. Chem. 16977

[47] Hopkins J and Badyal J P S 1996 Langmuir 124205

[48] Pothiraja R, Shanmugan S, Walawalkar M G, Nethaji M, Butcher R J and Murugavel R 2008 Eur. J. Inorg. Chem. 1834

[49] Murugavel R, Pothiraja R, Gogoi N, Clérac R, Lecren L, Butcher R J and Nethaji M 2007 Dalton Trans. 2405

[50] Snyder R G and Schachtschneider J H 1963 Spectrochim. Acta 1985 